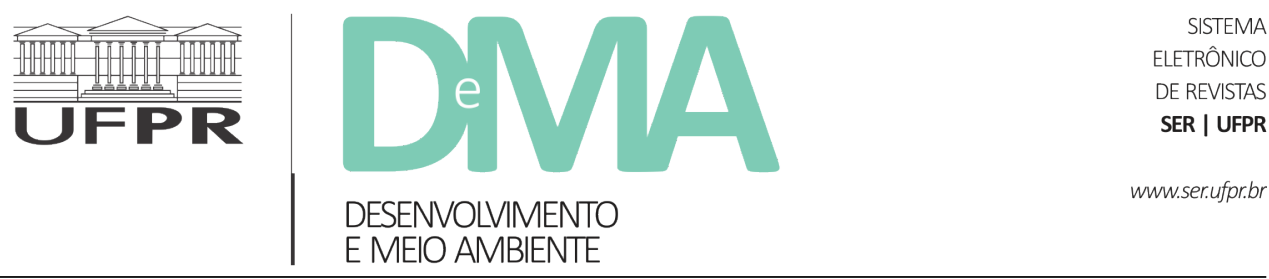

\title{
A (re)categorização de unidades de conservação e suas implicações aos modos de vida tradicionais
}

\section{The (re)cathegorization of conservation unities and its implications to traditional livelihoods}

\author{
Carina Catiana FOPPA ${ }^{1,2^{*}}$, Giovanna Carla BARRETO ${ }^{2}$, Francisco Quintanilha VERAS NETO ${ }^{3}$, Rodrigo Pereira \\ MEDEIROS $^{4}$ \\ ${ }^{1}$ Universidade Federal do Paraná (UFPR), Curitiba, PR, Brasil. \\ ${ }^{2}$ Programa de Pós-Graduação em Meio Ambiente e Desenvolvimento (PPGMADE), Curitiba, PR, Brasil. \\ ${ }^{3}$ Universidade Federal de Santa Catarina (UFSC), Florianópolis, SC, Brasil. \\ ${ }^{4}$ Centro de Estudos do Mar (CEM), Universidade Federal do Paraná (UFPR), Pontal do Paraná, PR, Brasil. \\ *E-mail de contato: ccfoppa@gmail.com
}

Artigo recebido em 29 de abril de 2018, versão final aceita em 29 de agosto de 2018.

RESUMO: O processo de criação, implantação e gestão das Unidades de Conservação é permeado por um cenário de disputas, no qual direitos e interesses das comunidades tradicionais têm sido subtraídos. As dinâmicas que configuram os territórios tradicionais não têm sido recepcionadas pelo espaço legalmente protegido da Unidade de Conservação, com diferentes implicações a partir dos seus objetivos de conservação e categoria de gestão. Isso reafirma o contexto de vulnerabilidade dos territórios com implicações diretas para manutenção dos modos de vida tradicionais, a diversificação das atividades, os modos de apropriação, a soberania alimentar, as condições de adaptação e mudança, incluindo-se riscos à sustentabilidade do ambiente. Como recorte deste artigo, são mobilizados dois contextos de análise. Em um, associam-se os processos de licenciamento e compensação ambiental de grandes empreendimentos na zona costeira ao processo de criação de Unidades de Conservação arbitrariamente de proteção integral em detrimento de Reservas Extrativistas (Resex) e de Desenvolvimento Sustentável (RDS). Tal condição fragiliza os ativos humanos, sociais, físicos, econômicos e naturais que compõem os modos de vida e, consequentemente, o território das populações tradicionais. Em outro, o contexto de recategorização de Unidades de Conservação desvia o espaço de gestão ao envolver outras organizações-ponte, como o judiciário, esboçando cenário que reafirma o contexto de vulnerabilidade das comunidades tradicionais, já que a dimensão das instituições informais e de expressões do território não são consideradas. Como arcabouço analítico, o artigo apresenta 
a perspectiva dos Modos de Vida Sustentáveis (Sustainable Livelihoods Approach). O enfoque na visão não disjuntiva das dimensões humanas, ambientais, políticas e institucionais articula elementos da criação, gestão e recategorização das Unidades de Conservação que influenciam o contexto de vulnerabilidade e os ativos que compõem os modos de vida de territórios tradicionalmente ocupados.

Palavras-chave: modos de vida tradicionais; territórios tradicionalmente ocupados; unidades de conservação; licenciamento ambiental; categorias de gestão.

ABSTRACT: The process of creation, implementation and management of Conservation Units is permeated by a scenario of disputes, in which the rights and interests of traditional communities have been subtracted. The dynamics that make up the traditional territories have not been considered by the legally protected area of the Conservation Unit, with different implications from their conservation objectives and management category. This reaffirms the context of vulnerability of territories with direct implications for the maintenance of traditional livelihoods, diversification of activities, modes of appropriation, food sovereignty, conditions of adaptation and change, including risks to the sustainability of the environment. As a framework for this article, two contexts of analysis are mobilized. In one, the processes of licensing and environmental compensation of large enterprises in the coastal zone are associated to the process of creating Conservation Units, arbitrarily in the category of integral protection, in detriment of Extractive Reserves (Resex) and Sustainable Development Reserves (RDS). Such a condition weakens the human, social, physical, economic and natural assets that make up the ways of life and, consequently, the territory of the traditional populations. In another, the context of the re-categorization of Conservation Units deviates the management space by involving other bridging organizations, such as the judiciary, outlining a scenario that reaffirms the vulnerability context of traditional communities, since the dimension of informal institutions and territorial expressions are not considered. As an analytical framework, the article presents the perspective of Sustainable Livelihoods Approach. The focus on the non-disjunctive view of human, environmental, political and institutional dimensions articulates elements of the creation, management and re-categorization of Conservation Units that influence the context of vulnerability and the assets that make up the livelihoods of traditionally occupied territories.

Keywords: traditional livelihoods; traditional territory; protected areas; environmental licensing; management categories.

\section{Introdução}

O processo de criação, implantação e gestão de Unidades de Conservação (UCs) tem sido permeado por um cenário de disputas, em que direitos e interesses das comunidades tradicionais têm sido subtraídos (Diegues, 2008; Acserald, 2009; Acserald \& Bezerra, 2010).

O não reconhecimento das ontologias que pautam as práticas, saberes e conhecimentos que as comunidades tradicionais historicamente empreendem em benefício da biodiversidade afeta negativamente os mecanismos sociais criativos de renovação e adaptação, acumulados e transferidos entre gerações. Tais práticas, saberes e conhecimentos são um meio de subsistência dos grupos sociais (Holling et al., 1998; Berkes et al., 2000; Morales et al., 2017; Hallam \& Bennett, 2018).

O reconhecimento científico e jurídico do papel das comunidades tradicionais na gestão e conservação dos recursos naturais encontra pouco respaldo no campo político e de tomada de decisão, ainda fortemente centrados no modelo "comando e controle" (Holling \& Meffe, 1996). O próprio 
papel da ciência tem sido distorcido: muitas vezes, fatos e dados são selecionados e interpretados de acordo com interesses políticos, criando cenários de incertezas e descontinuidades (O'Riordan, 2000).

A zona costeira brasileira vem mudando rapidamente devido à implantação de empreendimentos vinculados ao setor turístico-imobiliário, industrial e portuário. Em virtude do seu significativo impacto ambiental, essas transformações têm se relacionado diretamente com o Sistema Nacional de Unidades de Conservação (SNUC) (Brasil, 2000), fortalecendo a criação de Unidades de Conservação (UCs) de proteção integral como instrumento de compensação ambiental.

As pesquisas que tratam dos conflitos decorrentes da implantação de UCs com regime de proteção integral em territórios usados pelas comunidades tradicionais (Diegues, 1999; Diegues, 2008; Almudi \& Kalikoski, 2010; Barreto, 2017) apontam a necessidade de considerar as dimensões humanas para alcançar êxito e efetividade no mandato duplo de conservação e desenvolvimento na criação dessas áreas (FAO, 2011; Bennett \& Dearden, 2014). No entanto, a política ambiental enrijece a expressão de arranjos institucionais de gestão que permitiam o uso prolongado dos recursos naturais locais, comprometendo a subsistência e os modos de vida de gerações. Da mesma forma, fragilidades em compatibilizar conservação e desenvolvimento nessas áreas de especial proteção intensificaram os conflitos socioambientais na zona costeira brasileira (Bavinck et al., 2017).

O olhar analítico desses processos, contornado pelos princípios do ecodesenvolvimento (Sachs, 1986), ou da sua versão mais atual, o Desenvolvimento Territorial Sustentável - DTS (Vieira \& Cazella, 2004; Vieira et al., 2006), oferece pistas para uma compreensão normativa de planejamento e gestão. A partir do enfoque integrado das dimensões humanas e ambientais, buscamos investigar como processos políticos e institucionais da criação, gestão e (re)categorização das UCs têm influenciado o contexto de vulnerabilidade e os elementos que compõem os Modos de Vida Sustentáveis (MVS) das comunidades tradicionais. Argumenta-se que tais processos têm sido direcionados para a criação de UCs de proteção integral, impactando os modos de vida das comunidades tradicionais, em detrimento de categorias que têm potencial para recepcionar suas demandas, como as reservas extrativistas ou de desenvolvimento sustentável.

O artigo está organizado em três seções. A primeira situa o contexto das unidades de conservação na zona costeira, recuperando o seu posicionamento junto aos empreendimentos de significativo impacto ambiental. Como guia da discussão proposta, parte-se de um estudo de caso no litoral de Santa Catarina, com sobreposição entre territórios tradicionalmente ocupados e unidades de conservação. $\mathrm{Na}$ segunda seção, apresenta-se a abordagem dos MVS e sua relação com a dimensão territorial do desenvolvimento. A terceira apresenta os resultados do modelo analítico e coloca em evidência os ativos territoriais, o contexto de vulnerabilidade e as dimensões sociopolíticas relacionadas às diferentes categorias de UC.

\section{Controvérsias da (re)categorização das Unidades de Conservação}

Os resultados positivos e lições aprendidas de experiências exitosas de gestão dos recursos naturais com protagonismo e participação dos usuários 
(Queiroz, 2005; Kalikoski et al., 2009) têm sido pouco considerados nos processos de criação e implantação de UC.

Esse contexto opõe-se à bibliografia sobre áreas protegidas, que relacionam sua efetividade associada à dimensão social e humana, com destaque para: i) os modos de vida, ii) resultados socioeconômicos, iii) contexto social, econômico, cultural e ecológico, iv) fatores como história, política, mudanças tecnológicas e climáticas e iv) questões de escala (metas globais e realidades locais) (FAO, 2011; Bennett \& Dearden, 2014).

No Brasil, as distintas categorias de UCs existentes no SNUC experimentam condições distintas de gestão participativa que vão desde o controle majoritário do estado (via conselhos consultivos) até a promoção da participação direta dos usuários na tomada de decisão (via conselhos deliberativos) (Medeiros, 2009). Ou seja, de um lado, as unidades de conservação de proteção integral, cujos objetivos de gestão priorizam a preservação e manutenção das funções ecológicas de fragmentos ecossistêmicos considerados prioritários, e, de outro, as UCs de uso sustentável, como as Reservas de Desenvolvimento Sustentável (RDS) e as Reservas Extrativistas (Resex), orientadas para a proteção e conservação dos modos de vida das populações tradicionais. Ainda, numa terceira linha, como categorias "intermediárias", as Áreas de Proteção Ambiental (APAs) têm provocado reflexões sobre sua efetividade, considerando a permissividade que resulta dos usos privados em seus limites territoriais (Foppa, 2009; Foppa \& Medeiros, 2012).

A interpretação que decorre dessa linha de argumentação é a de que nas distintas categorias são observados conflitos, com impasses no processo de criação e/ou implementação (Vivacqua,
2012), da qual se atrela ineficiência em lidar com processos de compatibilização de políticas e diminuir os abismos entre as pautas da conservação e do desenvolvimento.

Dentre as 313 UCs federais brasileiras, apenas $43 \%$ possuem plano de manejo (ICMBio, 2014). Isso demonstra que os instrumentos de gestão e mecanismos de avaliação e monitoramento de sua efetividade, mesmo no que tange aos aspectos ecológicos, são ainda bastante incipientes. Entretanto, os mecanismos de controle e fiscalização dos usos dos recursos pelas populações tradicionais têm se intensificado historicamente. Por outro lado, mecanismos para regular o estabelecimento de empreendimentos de significativo impacto ambiental costumam ser negociados com condescendência.

No estado de Santa Catarina, as restrições ambientais impostas pelas UCs de proteção integral têm induzido processos de recategorização. Isso se dá mais para flexibilizar as normas, do que para criar mecanismos robustos de gestão que envolvam as diferentes pautas da zona costeira.

Por exemplo, no Parque Estadual da Serra do Tabuleiro, porções da UC localizadas em áreas litorâneas foram transformadas em três APAs costeiras, negligenciando os contornos legais, as demandas sociais e as configurações ecossistêmicas, resultando em Ação Direta de Inconstitucionalidade (ADIN da Lei 14.661/2009). Outras iniciativas foram observadas na Reserva Biológica Marinha (REBIO) do Arvoredo, com proposta de recategorização para parque nacional, mobilizadas pela indústria do turismo da região muito mais do que pelos passivos gerados aos pescadores artesanais daquela região (Vicacqua, 2005; Medeiros, 2009).

Em outros casos, como do Parque Estadual do Acaraí (região norte de Santa Catarina) e do 
Parque Nacional Aparados da Serra (região sul de Santa Catarina), os tensionamentos ocorrem por demandas da comunidade tradicional (Spalonese, 2013; Foppa, 2015). Mas o que se observa nesses casos são mecanismos de gestão orientados pelo "comando e controle" ou pelo "mito da natureza intocada" (Diegues, 1996), semelhantes àqueles que pautaram a criação de parques nacionais em meados da década de 1930 (Drummond Câmara, 2013).

Portanto, há duas grandes controvérsias: por um lado, motivado principalmente pelos interesses privados, cria-se espaço para o pleito de recategorizar UCs de proteção integral para categorias de uso sustentável. Por outro, negligenciando os direitos fundamentais das comunidades tradicionais, prioriza-se o estabelecimento de categorias de proteção integral em detrimento das Resex e RDS.

\subsection{Território Acaraí: um contorno de análise}

O território Acaraí, localizado em São Francisco do Sul (SC), é tradicionalmente ocupado por diferentes grupos étnicos que desenvolvem a pesca, atividades extrativistas e resguardam o patrimônio material, imaterial e os sistemas de conhecimento. Associações não governamentais ambientalistas reivindicaram a implementação de um parque no município, sendo a demanda efetivada como medida compensatória da instalação empreendimento industrial na região ${ }^{1}$.

O processo que antecedeu a sua criação não contemplou o entendimento das relações socioculturais e os efeitos de uma Unidade de Conservação de proteção integral na tradicional idade dos grupos. Por conta disso, foi promovida a Ação Civil Pública ${ }^{2}$, com pedido de suspensão da criação da Unidade de Conservação, por entender inadequada a categoria de proteção integral (Foppa \& Medeiros, 2011; Foppa, 2015).

\section{A abordagem dos modos de vida sustentáveis e a dimensão territorial do desenvolvimento}

A abordagem dos MVS é uma ferramenta conceitual utilizada para examinar as estratégias de gestão e desenvolvimento, numa perspectiva não setorial (Allison \& Ellis, 2001). A combinação dos conceitos indica ligações e resulta na dimensão dos modos de vida (Chamber \& Conway, 1991; Scoones, 1998; Farrington et al., 1999; Knutsson, 2006) (Figura 1).

Allison \& Badjeck (2004), entretanto, consideram a pouca compreensão das complexidades escondidas nos termos comunidade e tradição que, para a realidade brasileira, dialoga com a Política Nacional de Desenvolvimento Sustentável dos Povos e Comunidades Tradicionais - PNPCT (Brasil, 2007). Outras críticas permeiam sua utilização (Alisson \& Horemans, 2006) e, por isso, justificam a combinação analítica com a dimensão territorial do desenvolvimento, destacando-se a perspectiva histórica da trajetória de desenvolvimento com aprofundamento dos vetores de mudanças ao longo do tempo (Sabourin \& Teixeira, 2002; Cazella, 2006; Foppa, 2015).

\footnotetext{
${ }^{1}$ Com base no artigo 36 da Lei 9.985/2000 (Brasil, 2000), foi criado o Parque Estadual do Acaraí.

${ }^{2}$ Ação Civil Pública no 061.07.009145-6 (Comarca de São Francisco do Sul - 2a Vara) pelo Ministério Público Estadual e Federal.
} 


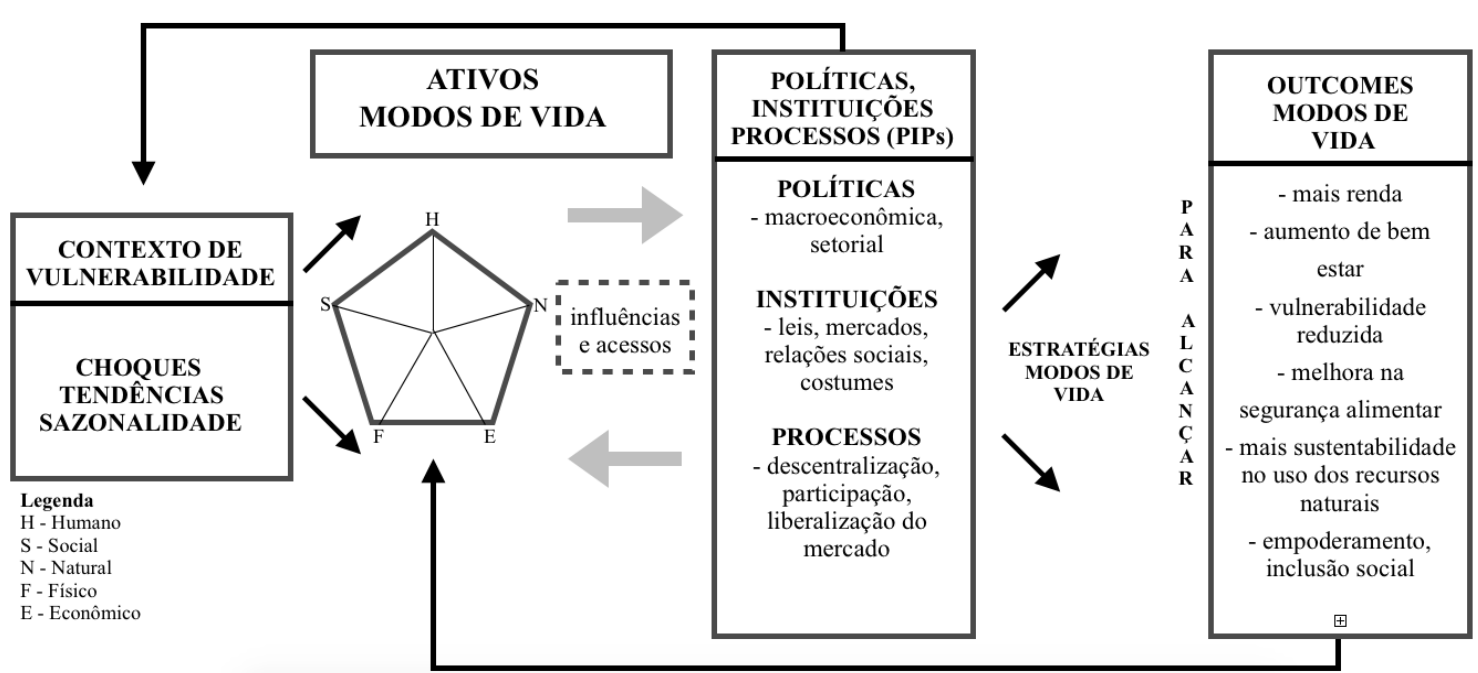

FIGURA 1 - Modelo de Análise dos Modos de Vida Sustentáveis.

FONTE: Traduzido de Farrington et al. (1999) e Allison \& Horemans (2006).

Os tópicos seguintes consistem numa análise descritiva da controvérsia de criação de uma UC de proteção integral no território do Acaraí, seguindo as etapas do modelo: i) ativos dos modos de vida, ii) contexto de vulnerabilidade, iii) políticas, instituições e processo e iv) outcomes modos de vida. Os dados foram coletados em nove meses de imersão na comunidade, entre setembro de 2010 e junho de 2011, com aproximadamente trinta e dois interlocutores (vinte e três homens e nove mulheres), com idade entre 30 e 86 anos. A metodologia foi orientada pela pesquisa qualitativa, com história oral, entrevistas, mapeamento participativo e observação participante. Dados secundários foram levantados e triangulados com os demais dados coletados para descrever e analisar os elementos que compõe o território analisado.

\section{Um território tradicional em movimento}

\subsection{A trajetória de desenvolvimento e modos de vida}

A trajetória de desenvolvimento do Território Acaraí demonstrou ciclos produtivos marcados pela pluriatividade (Figura 2), compartilhados entre diferentes famílias e núcleos comunitários ao longo de seis gerações.

O ciclo 1 retrata período em que os regimes de trocas alimentavam as atividades produtivas. Os ciclos 2 a 5 marcam o início de novas atividades produtivas, o abandono seletivo de outras e o retorno de atividades realizadas em ciclos anteriores. A pesca e a relação com a floresta estão presentes em toda a trajetória e, de forma mais remota, a caça. 


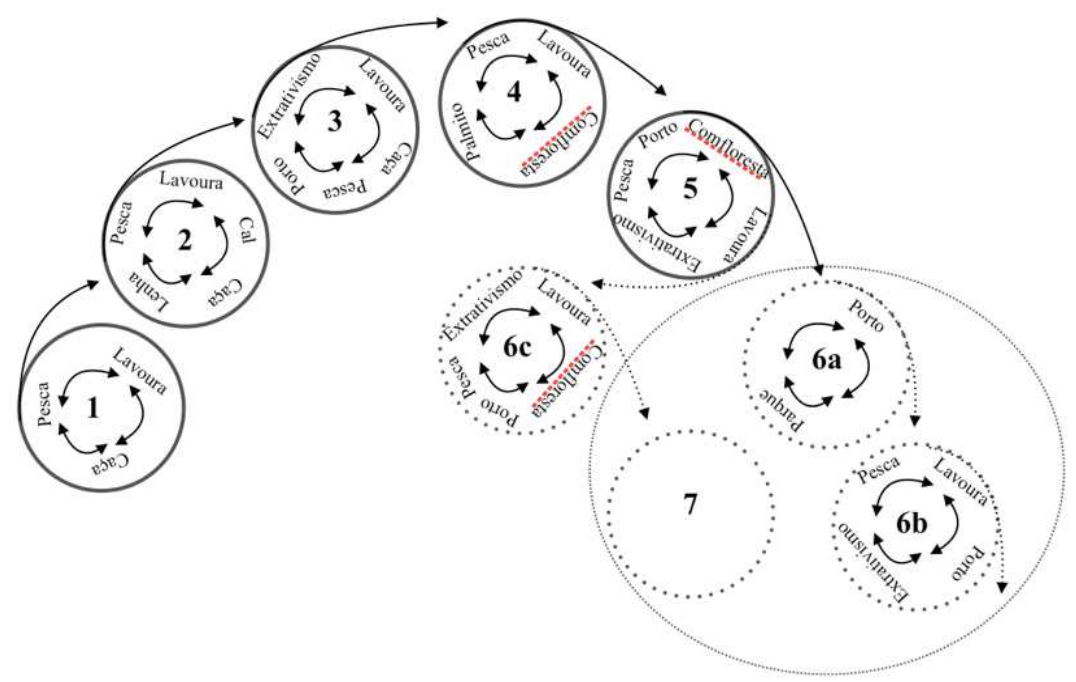

FIGURA 2 - Ciclos produtivos com pluriatividades e tendências possíveis de novas medidas de gestão.

Algumas atividades, como o porto e a silvicultura (Comfloresta), tornaram-se vetores de mudanças aos circuitos produtivos e provocaram alterações na dinâmica das atividades. A atividade portuária compôs o repertório das pluriatividades, considerando que não houve o abandono completo das atividades tradicionais, e sim a conciliação entre elas. Uma interpretação possível resulta de que a participação nessas atividades não afetou diretamente a manutenção das práticas tradicionais. Já o estabelecimento da Comfloresta alterou a composição da paisagem e dos modos de apropriação. A extração da samambaia (extrativismo) esteve presente em diferentes fases, reflexo das pressões exercidas pelo circuito comercial liderado por fatores externos à comunidade, como os atravessadores.

A dimensão imaterial retratada pelo conhecimento ecológico tradicional e a dimensão simbólica inerente a cada atividade produtiva coexistem em todos os ciclos produtivos e compõem os ativos humanos e sociais, abordados na seção seguinte.
No entanto, o perfil da comunidade se altera a partir da presença de grupos sociais heterogêneos que passam a compartilhar o mesmo território em mudança. Essa alteração é comum na zona costeira, tendo em vista a consolidação urbana de muitos balneários, condicionando a migração para áreas em busca de características culturais e ambientais mantidas pela comunidade tradicional. Assim, novas pressões oriundas do turismo, especulação imobiliária, segunda residência e pesca esportiva marcam os circuitos do território Acaraí e definem um cenário de mudança que exige adaptação da comunidade tradicional.

O ciclo 6 apresenta ramificações e pode ser interpretado a partir do ciclo que envolve a criação do parque (6a), com tendência de inviabilizar as atividades tradicionais. $\mathrm{O}$ porto poderia também ser retratado por qualquer atividade associada ao modelo de desenvolvimento do litoral norte catarinense, como o turismo, atividades industriais ou de serviços. Todas elas implicam erosão dos modos 
de vida tradicionais, já que o impedimento de permanecer no território pode induzir a migração para essas atividades de forma definitiva.

Em outra linha (6b), uma possível tendência se projeta para uma nova organização produtiva, resultante da intervenção do parque para conciliar na sua gestão o território tradicional. Já o ciclo (6c) representa um ciclo provável, a partir da reorganização do território, sem a intervenção do parque, proporcionada pelo aporte das organizações-ponte via processo jurídico de recategorização. Essa possibilidade poderia induzir a existência de um novo ciclo (7), inerente ou não à gestão do parque, assimilado pela alteração da categoria de proteção integral para Reserva Extrativista ou de Desenvolvimento Sustentável.

\subsubsection{Como se comportam os ativos}

As categorias de ativos se relacionam entre si, conforme disposição pentagonal (Figura 1). Assim, apesar de apresentados separadamente, eles devem ser compreendidos na sua interação (Tabela 1).

O capital físico das famílias que possuem vínculos com a pesca é traduzido pelos barcos, motores e redes, geralmente utilizados de forma compartilhada. A parceria na pesca ocorre entre um membro da comunidade que detém o capital físico e outro(s) que nem sempre possuem os petrechos de pesca, mas dispõem de capital humano para o exercício da atividade (ou conhecimento da pescaria ou saúde a ser traduzida no esforço manual).

TABELA 1 - Ativos do Território Acaraí.

\begin{tabular}{|c|c|}
\hline \multicolumn{2}{|r|}{ Ativos Território Acaraí } \\
\hline Humano & $\begin{array}{l}\text { - } \quad \text { Sistema de conhecimento da dinâmica do estuário e da floresta; } \\
\text { - } \quad \text { Envelhecimento das famílias; } \\
\text { - } \quad \text { Mulheres vinculadas à atividade produtiva de extração e pesca (questão de gênero); } \\
\text { - } \quad \text { Trabalias afrodescendentes; } \\
\text { Trabo parceira. }\end{array}$ \\
\hline $\begin{array}{l}\text { Econômico } \\
\text { (Financeiro) }\end{array}$ & $\begin{array}{l}\text { - } \quad \text { Reduzido acúmulo de capital; } \\
\text { - } \quad \text { Benefícios sociais e financeiros (aposentadoria da pesca; seguro defeso); } \\
\text { - } \quad \text { Rendas alternativas de trabalhos vinculados às atividades não tradicionais. }\end{array}$ \\
\hline
\end{tabular}


Embora o capital físico traduzido pelos motores dos barcos permita uma maior circulação ao longo do estuário, ele não necessariamente resulta em maior apreensão de recursos e/ou migração para outros ambientes, considerando que são raras as migrações ao ambiente marinho adjacente por parte dos que residem nos núcleos comunitários mais próximos ao interior do estuário. Por isso, considerar apenas os petrechos como critério de compreensão da comunidade tradicional apresenta-se limitado. Adiciona-se, portanto, que o capital físico se relaciona diretamente com o capital social e humano, em que a relação com os territórios se dá pelo senso de pertencimento e reprodução simbólica, semelhante ao relatado por Diegues (1996) e Almudi \& Kalikoski (2009) em outros territórios tradicionais.

As migrações ao ambiente marinho estão vinculadas à retirada do manini e ocorrem, normalmente, associadas aos circuitos simbólicos/ imateriais, como ida ao cemitério ou ao Casqueiro, ambos afetados pela delimitação do Parque. O capital físico vinculado à pesca, portanto, não alimenta somente as relações produtivas (ativos naturais), mas também as dimensões imateriais (ativos humanos) presentes no território, em relações de mútua dependência. As parcerias de pesca, por exemplo, fortalecem os laços sociais combinando ativos humanos e físicos para sustentá-la.

A aquisição do capital físico geralmente provém de aportes do capital financeiro, resultantes de políticas de benefícios (seguro-defeso, por exemplo), aposentadoria ou heranças e, em menor grau, dos lucros absorvidos na realização das atividades produtivas. Os aportes esporádicos com a realização de atividades temporárias, ou confecção de petrechos no próprio núcleo comunitário, também alimentam o capital físico existente. Durante o verão as mulheres pescam cará, atividade que exige pouco capital físico, considerando os petrechos associados (linha e anzol). Por outro lado, essa atividade vincula-se fortemente aos ativos humanos, pois está associada a práticas de lazer e perpetuação dos conhecimentos nas e entre famílias. As mulheres vinculadas ao extrativismo adotam um circuito multivariado, com a extração de samambaia a outras atividades vinculadas à natureza, como a pesca, hortas e outros serviços informais. Disso, resulta interpretação de que compreender ativos em nível de grupo produtivo não seria adequado. O entendimento das estratégias individuais, considerando o perfil de cada um na condição familiar, bem como dos meandros que envolvem as condições de gênero (se solteiras, se casadas, se divorciadas, com ou sem filhos) retrataram uma composição mais realista das relações entre ativos e que compõem as estratégias multivariadas.

A coesão entre os membros de uma mesma família em torno da atividade de extração da samambaia é mediada pelos ativos sociais, cujas relações de parentesco (trabalho realizado entre irmãs) e hierarquia familiar (membro mais velho pai/irmão), regulam as atividades, mesmo quando subordinados ao "patrão" externo aos vínculos familiares/comunitários. $\mathrm{O}$ fato de ir ou não ir participar da extração de samambaia, por exemplo, demonstra certa coesão que resulta da necessidade de manter um controle relativo da produção e dos preços definidos pelo patrão. A flexibilidade nos dias trabalhados oferece pistas de algum controle por parte de quem não controla os circuitos financeiros e considera um maior preço ao sistema de conhecimento adquirido. Retrata, também, outras necessidades que compõem os circuitos vinculados 
às mulheres que vão além das atividades produtivas e incluem: o cuidado com os filhos, idas ao médico, cuidado de familiares mais velhos, etc.

A estratégia de compartilhar a atividade entre irmãos, ou membros da família, é tática adotada para regular de alguma forma as relações envolvidas na atividade extrativista. Isso, no entanto, não significa dizer que o capital humano e social esteja desenhado para mediar e controlar o poder dos atravessadores e patrões em relação aos extrativistas diretos. Condições de fragilidade do capital financeiro disponível parecem ainda ser determinantes para limitar o encorajamento de outras estratégias de cunho social e institucional relacionado à atividade extrativista.

As negociações entre os grupos extrativistas e os "guardas" da Comfloresta para acessar as áreas privatizadas de extrativismo são mediadas pelos patrões e não contam com a participação direta das mulheres. Disso, também podem decorrer conflitos, considerando que a legitimidade de alguns fica omitida perante o poder de acesso e trama de outros grupos ou indivíduos mais empoderados economicamente/socialmente no escopo daquele circuito produtivo.

Os ranchos de pesca constituem também importantes elementos do capital físico e têm sido mantidos por gerações via compartilhamento familiar e comunitário. Os ranchos auxiliam na reprodução das atividades tradicionais e relações simbólicas. Capital financeiro é direcionado para manutenção desse capital físico que tem sofrido perdas, considerando as políticas ambientais incidentes (da Unidade de Conservação ou do Código Florestal), que muitas vezes proíbem a ampliação ou criação de novos ranchos de pesca.

Ao mesmo tempo em que o limitado capital financeiro é investido para manter os ativos físicos necessários, inclusive para segurança alimentar, as políticas ambientais incidentes não se operacionalizam por sanções graduais ou pelo diálogo com os direitos dos grupos tradicionais. Assim, o abandono/destruição do capital físico (ranchos), mantido secularmente por algumas famílias, tem sido perpetrado por medo de coerção e de sanções mais drásticas (multas) o que comprometeria o já escasso capital financeiro das famílias.

Não obstante o capital físico e financeiro vinculado às famílias pesqueiras possam ser considerados limitados, os capitais humano, social e natural possuem importante expressão. O sistema de conhecimento sobre o estuário, as regras locais e costumes que mantêm com as atividades produtivas possibilitam uma relação com os ativos naturais numa perspectiva de continuidade e sustentabilidade dos recursos. O trabalho familiar marca as atividades. Os mais novos auxiliam com a força de trabalho aqueles que já não têm saúde e idade para continuidade das atividades. O repertório do "saber fazer" amplia-se às outras atividades (tradicionais ou não), distanciando do processo de intensificação das capturas e de maiores investimentos em capital físico para compor pescarias com maior rendimento.

Uma série de recursos ou combinação de ativos/capitais é necessária para definir estratégias de modos de vida. Se a intensificação da agricultura/ extrativismo/pesca não foi caminho trilhado pelos grupos, seja pela limitação de capital financeiro, seja pelos impedimentos resultantes da privatização das áreas geridas comunitariamente, o capital social se revitalizou, fortalecendo regras de uso e acesso aos ativos disponíveis ao longo do tempo. De tal modo, o contexto histórico dinâmico e os diferentes recursos foram combinados na busca de diferentes estratégias de modos de vida, sendo, portanto, fun- 
damentais para a interpretação da constituição das estratégias adotadas ao longo do tempo (Scoones, 1998).

As limitações em alguns ativos podem dificultar que as famílias, indivíduos ou comunidades dependentes de recursos atravessem os limiares críticos de perturbações, ainda que sejam pequenas e conduzam à resistência dos modos de vida (Armitage, 2007). Nesse caso, as limitações de capital financeiro e físico dos extrativistas vinculados à samambaia podem intensificar o cenário de dependência aos atravessadores, resultando em abandono da atividade ou na intensificação da extração e, ainda, em limitações na renda que não garanta a segurança alimentar.

Esse cenário pode fazer com que o sistema caminhe "para trás", num limiar crítico caracterizado pela pobreza e vulnerabilidade (Armitage, 2007). Os aspectos do equilíbrio dinâmico das relações socioecológicas e da diversificação das estratégias que marcam o território no estabelecimento das políticas públicas se complexificam com a existência de UC de proteção integral.

Bennet \& Dearden (2014) também sugerem que o desenvolvimento de modos de vidas alternativos muitas vezes requer atenção para a construção de capacidades locais, por meio do aumento do capital financeiro e humano, bem como dos ativos físicos. Demanda real está desenhada para os grupos extrativistas que relataram necessidades relacionadas aos capitais físicos para melhoramento das atividades, como infraestrutura para o transporte das samambaias e local para armazenamento.

Sobre os ativos naturais, importante incongruência se revela. A trajetória de desenvolvimento demonstra relação da comunidade com o território que remonta cerca de 450 anos (seis gerações) por modos de apropriação comunal e regramentos informais de gestão dos recursos de uso comum. Isso resultou na manutenção de fragmentos ecossistêmicos em grau de conservação condizentes com a vocação exigida para criação de Unidade de Conservação de proteção integral. Embora seja visível na paisagem que recobre o território tradicional, os operadores da política, por suas epistemes, ou interesses, não são capazes de correlacionar essas variáveis e considerar que a UC é quem se sobrepõe ao território tradicional, não o contrário.

\subsection{O contexto de vulnerabilidade}

O modelo de análise dos modos de vida retrata os ativos do pentágono e sua correlação com o contexto de vulnerabilidade. A Tabela 2 apresenta as variáveis de tendências e choques que puderam ser absorvidas nesta análise, a partir de uma perspectiva histórica com variações endógenas e exógenas.

TABELA 2 - Principais tendências e choques do contexto de vulnerabilidade do Território Acaraí

\begin{tabular}{lll}
\hline \multicolumn{1}{c}{ Tendências } & Contexto de Vulnerabilidade \\
\hline - & Políticas desenvolvimentistas & Choques \\
\hline & Conflitos de acessos & Privatização ou estatização das áreas de uso comum (modos de apropriação) \\
& & $\begin{array}{c}\text { Mudanças ambientais no estuário (depleção dos recursos, interferência na } \\
\text { dinâmica natural) e na paisagem }\end{array}$ \\
\hline
\end{tabular}

- $\quad$ Presença de Unidade de Conservação de Proteção Integral 
A UC foi considerada como tendência (benigna ou não) e como choque. Num primeiro horizonte, como choque ${ }^{3}$, com implicações em termos de acesso e fortalecimento/enfraquecimento dos ativos com a sua criação. Num segundo horizonte, em termos de instituições e capacidade adaptativa, configura-se como uma tendência que reafirma o contexto de vulnerabilidade.

Os choques dizem respeito às mudanças ambientais relacionadas ao estuário do Acaraí e dos modos de apropriação que resultaram em conflitos de acesso aos recursos materiais e simbólicos do território. O modelo desenvolvimentista da região foi colocado como tendência para pensar de que maneira ele impacta (impactou) os ativos que compõem a plataforma dos modos de vida. A UC comporta-se como um fator de bloqueio ou de reafirmação desse modelo, com grande aderência à categoria de gestão escolhida.

A presença da Comfloresta modificou as formas de apropriação dos recursos naturais e da paisagem, privatizando áreas e gerando conflitos com as atividades tradicionais ao longo do tempo. Vista como tendência ao longo da trajetória, atualmente apresenta-se como um choque, considerando a consolidação de um modelo que se perpetua em relação aos modos de apropriação comunais. Isso engessou possibilidades de gestão compartilhada das áreas de extração da samambaia entre os diferentes grupos, bem como de outras formas de manejo associado à agricultura familiar. Assim, o horizonte histórico incorporado na pesquisa clareou as modificadas relações entre os comunitários e as novas formas de apropriação, destacando o aprendizado e adaptações nos sistemas socioecológicos para diminuir choques e tendências.

\footnotetext{
${ }^{3}$ Os choques impactam diretamente os ativos.
}

Somado ao contexto atual da "estatização" do território pelo parque, mecanismos de renovação criativa de regulação do acesso, uso e modos de apropriação das áreas ficam desmobilizados, considerando o grau de incerteza sobre os direitos comunitários relacionados à nova medida de gestão. Por isso, a UC pode ser vista como tendência e/ou choque, considerando seus efeitos imediatos nas comunidades, com mecanismos de poder e coerção que traduzem a nova logica institucional.

A proibição dos usos diretos pelo parque e a privatização das áreas por empreendimentos no entorno, somado ao diminuído capital financeiro de que os grupos tradicionais dispõem, uma tendência de abandono das atividades pode ser desenhada. No caso das mulheres extrativistas, atualmente dependentes dos atravessadores/patrões e com escassos recursos financeiros, apresentam limitações relacionadas ao capital humano, em termos de saúde e condições de trabalho, mas ao mesmo tempo um saber adquirido sobre os circuitos da floresta que ficam ainda mais desconsiderados pela incompatibilidade com o Parque. Por outro lado, uma tendência pode revelar-se na sobrecarga do extrativismo e possível comprometimento dos recursos naturais, dada a ausência de mecanismos de controle e gestão compartilhada, bem a necessidade de um aporte de recursos financeiros oriundos da atividade para sustentação da família (filhos, marido).

O bloqueio do acesso e a reduzida capacidade de migrar para outras áreas para o desempenho da atividade, tendo em vista as limitações de logística (capital físico e financeiro), as famílias/grupos podem fortalecer a tendência de empregos formais vinculados à política de crescimento da região (portos, serviços gerais, industriais, como de alguma forma 
o fizeram no passado). Ou, na ausência desses, a redução massiva dos padrões de consumo pode ser ainda mais estabelecida, forçando a migração para atividades de menor sustentabilidade e, sobretudo, com grandes efeitos para o empoderamento, inclusão, valorização dos saberes, saúde e bem-estar das famílias e indivíduos.

Causas naturais de modificação dos recursos, seja pelo fechamento do Canal do Linguado ${ }^{4}$, seja pela ausência de ordenamento das atividades vinculadas à foz do Rio Acaraí (choques), direcionaram outras tendências, variando a combinação de outros ativos para superar os cenários de crise. No caso da pesca, o beneficiamento dos produtos capturados com a produção de cambira (peixe defumado) pode ser visto como uma condição para agregar valor ao produto, garantindo mais renda e a manutenção nas atividades tradicionais, mesmo num cenário de migração temporária e seletiva das atividades. As mudanças ambientais, contudo, retrataram choques ao longo da trajetória, alterando os ativos disponíveis e tensionando reformulação de outros ativos para alcançar novas estratégias de modos de vida.

\subsection{Políticas, instituições e processos (PIPs): reafirmação ou reversão do contexto de vulnerabilidade?}

O alcance dos modos de vida, associado a um repertório multivariado e diversificado de atividades, o qual inclui também atividades não tradicionais, exige um olhar aguçado perante as políticas, instituições e processos (PIPs) e ultrapassar o viés estritamente setorial.
O Brasil é um dos dezessete países que, juntos, possuem $70 \%$ da biodiversidade do planeta, sendo as unidades de conservação, as terras indígenas, os territórios quilombolas e de comunidades locais (caiçaras, seringueiros) um retrato da rica sociobiodiversidade que reúne inestimável acervo de conhecimentos tradicionais sobre a conservação e o uso da biodiversidade (Diegues, 2005). Entretanto, o modelo transversal de implementação de políticas públicas ainda não avançou na valorização da sociobiodiversidade, soberania alimentar e geração de renda (Vieira \& Cader, 2013). As políticas públicas incidentes na zona costeira não se encerram naquelas descritas nesta seção. Se tomadas como exemplos as políticas da pesca artesanal, um panorama restrito desvela-se, no sentido contrário de considerar importante atributo de que famílias de pescadores se envolvem em diferentes atividades, a fim de alcançar a segurança alimentar e reconhecer a complexidade cíclica e sazonal das estratégias de subsistência (Allison \& Ellis, 2001). Os autores mencionam como preceito fundamental que pensar à luz da abordagem dos modos de vida auxilia a identificar o que as pessoas têm, mais do que elas não têm, fortalecendo as soluções criativas em vez de substitui-las, bloqueá-las ou prejudicá-las, ou, ainda mais, singularizá-las em políticas setoriais e não transversais de conservação e desenvolvimento.

Nos territórios marinho-costeiros, o seguro-defeso, por exemplo, constitui medida que tem afastado inúmeras famílias da linha limítrofe da pobreza (Kalikoski \& Vasconcellos, 2012). Entretanto, atrela-se ao acesso da referida política pública a apresentação de uma série de documen-

\footnotetext{
${ }^{4}$ O fechamento do Canal do Linguado remonta ao ano de 1907, iniciado pelo fechamento da porção norte do canal, quando se objetivou a construção do ramal ferroviário de ligação ao Porto de São Francisco do Sul. Em 1935 foram concluídas as obras de fechamento total do canal. A comunidade tradicional percebe mudanças na dinâmica estuarina.
} 
tações relacionadas ao exercício da profissão, forçando um "autorreconhecimento" exclusivo como pescador(a), o que não retrata os movimentos de inúmeras comunidades tradicionais ao longo da costa brasileira.

Requisitos como: i) apresentação de documentos fiscais de venda do pescado e de adquirentes; ii) comprovação do exercício profissional da atividade de pesca artesanal em caráter ininterrupto e iii) o veto de vínculos de emprego, outra relação de trabalho ou outra fonte de renda diversa da decorrente da atividade pesqueira (Brasil, 2003), limitam o enquadramento para muitas famílias, exigem uma minuciosa análise de outras políticas associadas e dão um caráter excessivamente formal ao que se constitui na informalidade. No Território Acaraí, a exclusividade na pesca não retrata as estratégias adotadas para alcançar os modos de vida sustentáveis, mas é articulada como critério de cadastramento para dirimir o conflito que o parque ocasiona na comunidade tradicional. A intensificação da atividade pesqueira, para comprovar o caráter ininterrupto na atividade, teria que ser adotada, o que poderia ocasionar um circuito de migração para outras áreas de pesca e, consequentemente, acarretar conflitos com outros grupos e usuários em escala ampliada.

Além disso, os investimentos em capital físico e financeiro para desempenhar a exclusividade poderiam não traduzir a sustentabilidade pretendida dos recursos e as lógicas que pautam os ativos humanos e naturais. A diversificação geralmente constitui-se como fator favorável para a redução da vulnerabilidade, auxiliando na diminuição da insegurança alimentar e, sobretudo, proporcionando a base para construção de ativos que permitam às famílias construírem suas próprias rotas, somadas às melhoras na qualidade e sustentabilidade dos recursos naturais (Ellis \& Allison, 2004).

Nas reflexões associadas ao desenvolvimento, visto como um processo das liberdades que as pessoas desfrutam ("liberdades subjetivas"), considera-se a possibilidade de escolher a vida que a pessoa tem razão em valorizar. Se um modo de vida tradicional tem de ser sacrificado para escapar-se da pobreza devastadora ou da longevidade minúscula, então as pessoas diretamente envolvidas têm de ter a oportunidade de participar da decisão do que deve ser escolhido (Sen, 2000). A diversificação, nessa ótica, amplia as opções das pessoas em novas habilidades e experiências (Ellis \& Allison, 2004). Para o Território Acaraí, ela foi constituída no passado, reafirmada no presente, mas negada estruturalmente na tradução da política pública de conservação instituída pelo Parque.

Embora a prevalência de diversificação dos modos de vida seja reconhecida e, inclusive, recepcionada na Política Nacional de Desenvolvimento Sustentável dos Povos e Comunidades Tradicionais - PNPCT (Brasil, 2007), ainda há uma ampla margem para diferentes interpretações sobre o que isso significa, especialmente para as estratégias de redução da vulnerabilidade, estabelecimento de políticas e, sobretudo, na condução dos processos de criação e gestão de UCs.

A PNPCT (Brasil, 2007) assimila outra dimensão fundamental, a do autorreconhecimento, que para o Território Acaraí se concilia não somente às atividades produtivas, mas das territorialidades envolvidas. Observa-se que essas dimensões do autorreconhecimento e do impacto social da criação de áreas protegidas são ainda mais desconsideradas quando se intercruzam os processos de licenciamento às UCs e esvaziam as dimensões étnicas, raciais, 
simbólicas, relações de parentesco e de tradição envolvidas.

Desse feito, importa correlacionar o pontuado por Almeida (2008), que a Constituição Federal de 1988 (Brasil, 1988) e a Convenção 169 da OIT logram contemplar estas distintas situações sociais referidas às regiões de colonização antiga, assim como aquelas que caracterizam regiões de ocupação recente, ao recolocar no tempo presente o sentido de "terras tradicionalmente ocupadas", libertando-o da "imemorialidade", da preocupação com "origem", do passado e de categorias correlatas.

Numa revisão da literatura organizada por Agrawal (2002), sobre as características dos grupos e potenciais para ação coletiva, o autor observa que comunidades e grupos de usuários possuem condições e direito de organizar novos arranjos institucionais, mas em meio a grandes disputas, a sua resolução não ocorre sem a intervenção do Estado. Mas o papel do governo federal e estadual, segundo análise do autor, tem se constituído no envolvimento, em muitos casos, para transformar os modos de apropriação, antes comunais, em outros regimes relacionados.

A proibição do uso direto pelo parque rompe relações simbólicas dos comunitários com a natureza e provoca perdas do capital cultural e físico/ financeiro. Como visto nas autuações (multas, ações, etc.) dos órgãos ambientais que resultaram em alguns casos na demolição de ranchos, sem a prerrogativa da ampla defesa, ou mesmo no abandono ou na demolição voluntária por parte dos comunitários, considerando o receio da imposição de sanções pecuniárias. Situação semelhante foi encontrada no Parque Nacional Lagoa do Peixe, no Rio Grande do Sul (Almudi \& Kalikoski, 2009).
As sanções perpetradas pelos órgãos ambientais, incluindo-se aquelas associadas às UCs, embora se articulem como mecanismos de erosão dos modos de vida das comunidades, representam em via alternativa a capacidade de organização sociopolítica para enfrentamento do novo vetor de mudança (UC). Nessa linha, a presença de organizações-ponte (Cash et al., 2006), como o Ministério Público e Universidade, ampliam o acesso dos comunitários sobre seus direitos, traduzindo-se na estruturação de associações formais para enfrentamento da implementação do Parque, bem como da ampliação do repertório sobre as diferentes categorias de gestão do SNUC.

Embora o Ministério Público no início do processo tenha atuado de forma a promover o acesso a informações e a garantia dos direitos, o processo resultou na celebração de um Termo de Ajustamento de Conduta (TAC) ${ }^{5}$ para extinguir o "embargo" do Parque, sem, contudo, envolver as comunidades e considerar a recategorização aventada no início do processo.

Compõe-se, assim, um jogo de forças que polariza e fragiliza ainda mais as comunidades locais e fortalece o status de "natureza intocada" perpetrada pela UC de proteção integral com um protecionismo que reafirma a dimensão econômica, atrofia a dimensão cultural, étnica e territorial e é incompatível, inclusive, com as dimensões ecológicas. A exemplo disso, tem-se que emissário de resíduos industriais cruzam a $\mathrm{UC}$ e a foz do rio que justificou a sua criação, ficou fora dos limites legais da UC, com sérias implicações à manutenção das funções ecológicas daquele estuário.

Nota-se, no cenário norte catarinense, situação semelhante à abordada por Almeida (2012, p.

\footnotetext{
${ }^{5}$ TAC firmado em 2012, entre o Ministério Público Estadual, a FATMA e o Governo do Estado.
} 
63) na Amazônia, cuja implementação de políticas decorrem de "uma ação de Estado deliberadamente protecionista, voltada para a reestruturação de mercados", bem como de ações governamentais que flexibilizam normas jurídicas, que asseguram os direitos territoriais de povos e comunidades tradicionais, o que acaba por "debilitar os fatores identitários, atomizar os agentes sociais, fragilizando identidades coletivas, suas condições de representação e os próprios atos de delegação".

Esse processo demonstra via de mão única de aprendizagem institucional. Se, de um lado, observa-se reorganização sociopolítica da comunidade para atuar no novo modelo de gestão, em outra via, não se nota reorganização por parte dos órgãos gestores e outras instituições. No espaço formal do conselho gestor, as disputas decorrem da postura preservacionista dos gestores do Parque, somadas às pressões de Organizações Não Governamentais (ONGs), de cunho estritamente ambientalista que, em seus discursos e práticas, não consideram as dimensões étnicas, da história e da tradição da comunidade.

Há, nesse contexto, monopolização dos discursos em defesa do Parque, justificados pela possibilidade de obter recursos de compensações ambientais de empreendimentos da região, demonstrando distinção no manuseio dos critérios de preservação utilizados para as comunidades tradicionais, daqueles utilizados para compreender os efeitos de empreendimentos de significativo impacto na região. Há também incentivo ao "turismo ecológico", sem nenhuma correlação com áreas de relação simbólica da comunidade.
As tendências de cenários possíveis podem ser compreendidas em três linhas. De um lado, seria considerar a área sem proteções especificas (sem UC, por exemplo), de outro, a criação de UC de uso sustentável (recategorização do parque) ou, em outra via, a configuração de outra medida de gestão recriada pelos comunitários e organizações-ponte, desenhadas na perspectiva do Parque já criado (Tabela 3).

O cenário sem proteção específica induziria a consagração de um modelo desenvolvimentista fortemente associado à privatização das áreas, com loteamentos, condomínios e outros empreendimentos em expressão do litoral catarinense. Esse cenário provavelmente não garantiria os modos de vida da comunidade e reverteria os ativos naturais em grau possível de irreversibilidade. Esse cenário se apresenta como importante para pensar a tendência a ser desenhada, caso o parque não tivesse sido criado, ou para contextos similares em outras regiões litorâneas brasileiras.

Se observada a proposição genérica de recategorização do parque para UCs de uso sustentável, para o contexto do litoral catarinense, isso se revelaria como estratégia de empreendedores para o estabelecimento de $\mathrm{APAs}^{6}$. Esta categoria tem sido percebida como de maior permissividade ambiental e, a exemplo disso, a Lei Complementar 140/2011 (Brasil, 2011) criou diversas exceções para competência da União, dos Estados e dos Municípios nessa categoria, da qual decorrem fragilidades na condução de processos de licenciamento e fiscalização.

${ }^{6}$ Como visto no Parque Estadual do Tabuleiro ou no processo de criação de Reserva de Fauna na Baía da Babitonga. 
TABELA 3 - Possíveis cenários resultantes do contexto institucional e condição esperada dos ativos.

\begin{tabular}{|c|c|c|}
\hline $\begin{array}{c}\text { Contexto } \\
\text { Institucional }\end{array}$ & Ativos & Outcomes esperados \\
\hline $\begin{array}{l}\text { 1. Status quo } \\
\text { Parque não } \\
\text { implementado }\end{array}$ & H & $\begin{array}{l}\text { i) tendência de migração para outras atividades não tradicionais; ii) reduzido } \\
\text { capital físico e financeiro reafirmado pela ausência de políticas associadas; } \\
\text { iii) busca do aumento de capital físico e financeiro por meio da "chantagem } \\
\text { locacional", comprometendo os ativos sociais e humanos; iv) comprometi- } \\
\text { mento dos ativos naturais pela gestão incipiente e interferências externas e, } \\
\text { sobretudo, pelo modelo de desenvolvimento do norte catarinense; v) recria- } \\
\text { ção criativa dos grupos para reverter o cenário, via organização comunitária, } \\
\text { associativismo dos grupos vinculados às atividades }\end{array}$ \\
\hline 2. Com Parque & & $\begin{array}{l}\text { i) valorização acentuada dos ativos naturais; ii) cadastro do TAC que não } \\
\text { acomodaria todas as dimensões envolvidas (materiais e imateriais); iii) mais } \\
\text { injeções financeiras de compensação ambiental para reafirmar as dicotomias } \\
\text { natureza/sociedade; iv) organização social poderia se fortalecer, via organi- } \\
\text { zação comunitária, da reafirmação dos elementos endógenos e participação } \\
\text { de organizações-ponte; v) ausentes ou incipientes recursos provenientes de } \\
\text { políticas para incentivo das atividades tradicionais; vi) medidas de coerção } \\
\text { acentuada das atividades produtivas pela gestão do Parque (conselho con- } \\
\text { sultivo), ONGs, etc. }\end{array}$ \\
\hline $\begin{array}{l}\text { 3. Sem Unidade de } \\
\text { Conservação }\end{array}$ & & $\begin{array}{l}\text { i) semelhante ao cenário de status quo; ii) com maior agravamento para } \\
\text { manutenção dos ativos humanos, sociais e naturais, considerando a provável } \\
\text { tendência de ocupação da áreas por empreendimentos vinculados à lógica } \\
\text { desenvolvimentista da zona costeira norte catarinense; iii) possibilidade de } \\
\text { recriação da organização dos grupos sociais, a partir de políticas vinculadas } \\
\text { ao autorreconhecimento, via organizações-ponte. Menor possibilidade, } \\
\text { considerando o espaço-tempo necessário em contraposição ao cenário } \\
\text { desenvolvimentista. envolvidas (materiais e imateriais); }\end{array}$ \\
\hline $\begin{array}{l}\text { 4. Outra medida de } \\
\text { gestão }\end{array}$ & & $\begin{array}{l}\text { i) recriação da organização social, resultado do TAC, das organizações- } \\
\text {-ponte ou dos elementos endógenos do território; ii) compatibilização da } \\
\text { conservação e de direitos multiculturais, resultante dos elementos endógenos } \\
\text { em articulação com os processos, políticas e instituições em outros níveis; } \\
\text { iii) predisposição das organizações em diferentes escalas para composição } \\
\text { pretendida. }\end{array}$ \\
\hline
\end{tabular}


A recategorização da UC, ou mesmo a desafetação dos seus limites para acomodar as demandas da comunidade, estariam associadas ao estabelecimento de alterações na lei, o que acarretaria a intervenção da Assembleia Legislativa do Estado, complexificando ainda mais a recepção dos direitos das comunidades tradicionais. A previsão explícita de recategorização no SNUC está representada pela alteração de UCs de Uso Sustentável para UCs de Proteção Integral e não ao contrário ${ }^{7}$.

A compensação ambiental atrelada às UCs de Proteção Integral complexifica o cenário e apresenta-se como mais uma barreira para a recepção dos direitos tradicionais. A argumentação do órgão gestor no âmbito judicial foi pautada pela necessidade de atuar como receptáculo de recursos de compensação, o que ficaria inviabilizado, não existência de UC de Uso Sustentável. Essa argumentação também está presente nos discursos de entidades ambientalistas.

A possibilidade de recategorização na direção de uma RDS/Resex conciliaria os interesses da conservação da biodiversidade e do desenvolvimento das famílias/grupos. No entanto, isso não ocorreria sem intermináveis embates jurídicos e precisaria ser considerado a organização comunitária necessária para pleitear uma RDS/Resex, contornada por longos períodos para apreensão das informações atreladas aos trâmites legais. Além disso, dada a complexidade das relações do território (diferentes grupos e usos), o processo de autorreconhecimento naquele contexto precisaria ser inclusivo e conciliatório de muitas territorialidades, incluídas aquelas associadas às dimensões étnicas, ainda não consideradas por aqueles grupos.
No conjunto marinho-costeiro, no litoral sul catarinense, tem-se que as experiências articuladas para criação de Resex foram marcadas por processos com pouca efetividade nos processos de aprendizagem social, considerando o acirramento dos conflitos e da mediação por organizações governamentais que fortalecem os antagonismos entre meio ambiente/desenvolvimento e conservação da biodiversidade/direitos multiculturais (Vivacqua, 2012). Prioriza-se a configuração institucional, em detrimento da construção de processos efetivos de gestão participativa, com empoderamento, pertencimento, descentralização e co-responsabilização dos usuários de recursos (Sen \& Nielsen, 1996; Carlsson \& Berkes, 2005). Esses elementos antecedem a "co-gestão escrita" e marcam a essência da dinâmica de funcionamento das Resex. Ainda, recentes abordagens têm enfatizado a importância de que os processos de gestão de áreas marinhas protegidas incorporem a lógica dos modos de vida existente dentro dos seus limites, inclusive os mecanismos endógenos e preexistentes de tomada de decisão (Westlund et al., 2017). Em termos de objetivos a serem alcançados, a RDS acomodaria esses elementos, mas assumir os interesses comunitários e conselhos deliberativos não estão associados ao repertório cotidiano dos órgãos de gestão catarinenses.

A terceira via analisada (outra medida de gestão) poderia ser operacionalizada em conjunto das prerrogativas previstas no SNUC. Os termos de compromisso, estabelecimento de áreas de exclusão, criação de grupos de trabalho específicos para lidar com as expressões dos grupos tradicionais

${ }^{7}$ Ambas situações se depreendem da interpretação do artigo 22 do SNUC (Brasil, 2000). 
poderiam ser articulados e ser um passo intermediário para um possível processo de recategorização.

Em termos regionais, contudo, pensando no entorno e zona de amortecimento de uma UC de proteção integral, há que se considerar um balanço positivo, considerando que a sua presença impõe importantes exceções, ao menos no plano teórico da legislação. A leitura da Lei da Mata Atlântica e de Resoluções Conama relacionadas ao licenciamento ambiental conduzem exigências mais robustas na fase de realização dos estudos técnicos ${ }^{8}$ e dão maior garantia na proteção dos remanescentes florestais e de outras porções físicas das territorialidades da comunidade.

Entretanto, mesmo com essa regulamentação em potencial, não tem sido observada atuação diferenciada relativa às áreas de silvicultura, da ocupação imobiliária do entorno, ou das modificações aceleradas na foz do estuário que justificou a criação da UC. Assim, há que se considerar o impasse em que se inserem as comunidades no plano político-institucional, posto que "se ficar UC de proteção integral o órgão ambiental pega e se flexibilizar a categoria, os empreendimentos econômicos comem".

As incongruências que reafirmam o contexto de vulnerabilidade das comunidades são observadas nas distintas fases das UCs. Elas fortalecem as dicotomias e distanciam as possibilidades de convergência dos direitos comunitários e da conservação da biodiversidade, exemplificados por: i) estudos técnicos conduzidos com marcos epistêmicos que não consideram as comunidades tradicionais; ii) desconhecimento/fragilidade dos ritos do conselho gestor e do plano de manejo; iii) estrutura enrijecida do Conselho que não acomoda as regras informais e formas próprias de organização dos comunitários, iv) mediação do conselho realizada por profissionais que desconhecem as dinâmicas dos grupos, não têm afinidade em lidar com pessoas e centralizam as discussões em torno dos seus próprios interesses; v) desconsideração dos processos de ação, resistência e organização e da aprendizagem implícita e explícitas desses processos; vi) omissão das questões de gênero; vii) direcionamento de recursos oriundos de compensações ambientais que fortalecem o mito da natureza intocada da UC, fragilizando os ativos sociais, humanos, físicos e financeiros das comunidades.

\section{Considerações finais: por que não uma Resex?}

A combinação da abordagem MVS associada à dimensão territorial do desenvolvimento permitiu compreender os movimentos que marcam um território tradicionalmente ocupado. A dimensão não setorizada da abordagem MVS associada ao componente histórico do DTS ampliou a abrangência do modelo ao interpretá-lo como algo dinâmico e ativo, em vez de estático ou instantâneo. Como resultado, as atividades produtivas foram compreendidas e correlacionadas aos demais ativos do território (humanos, físicos, financeiros), nas quais estão presentes a informalidade, expressivo sistema de conhecimento tradicional e relações simbólicas

\footnotetext{
${ }^{8}$ A Lei 11.428/2006 (Brasil, 2006) normatiza no art. 11 importante restrição no corte e supressão de vegetação de mata atlântica no entorno de Unidades de Conservação. A Resolução Conama 428/2010 (Conama, 2010) menciona que num raio de 3 km de UCs de Proteção Integral será necessária a realização de Estudos de Impactos Ambientais (EIAs) de empreendimentos de significativo impacto ambiental, o que, em tese, acarretaria maior rigor na análise dos impactos.
} 
que constituem as territorialidades e estratégias dinâmicas para manter os modos de vida sustentáveis.

A heterogeneidade de grupos, as diferentes atividades e modos de apropriação dos recursos naturais opõem-se à rigidez dos processos de criação e implantação das UCS. Essa oposição se apresenta também nos processos de recategorização, especialmente pelas distintas epistemes das organizações-ponte, assim como dos interesses privados que se sobrepõem aos direitos fundamentais das comunidades tradicionais.

O imbricamento das UCs com o licenciamento ambiental alcança cenário ainda mais crítico, considerando que as compensações ambientais são absorvidas para fortalecer um modelo desenvolvimentista que se reafirma e se opõe à conservação ambiental e à manutenção dos modos de vida das comunidades tradicionais. Essas condições são essenciais para compreender os territórios afetados por UCs, mas têm sido invisibilizadas nos processos de criação, implantação, gestão e recategorização de UCs.

Os argumentos para a criação de unidades de conservação de proteção integral por meio de compensação ambiental preconizados no SNUC para o licenciamento ambiental desconsideram a possibilidade de que muitos dos espaços potenciais à proteção estão configurados como territórios tradicionalmente ocupados, situação que garantiu a vocação ambiental dessas áreas.

O licenciamento ambiental caracteriza-se como um processo que, por um lado, legitima a existência de atividades potencialmente poluidoras e, por outro, negligencia os territórios tradicionalmente ocupados, já que induz a criação de UCs de proteção integral que fragilizam ainda mais os modos de vida tradicionais e afastam a recepção de outras categorias mais adequadas, como as Resex e RDS. A exemplo do território Acaraí, o descompasso entre a dinâmica institucional e a complexidade dos modos de vida cria efeitos diretos sobre a eficiência de gestão e resiliência dos sistemas socioecológicos (Folke et al., 1998; 2007).

Desconsiderar a presença de populações tradicionais e suas dinâmicas direciona a falhas na concepção das áreas marinhas protegidas. $\mathrm{O}$ "passo-zero" da criação de áreas marinhas protegidas, fase primária de definição de objetivos e de novos contratos sociais entre os diversos atores, é uma das bases estruturantes da governança de áreas marinhas protegidas (Chuenpgadee \& Jentoft, 2007; Chuenpagdee et al., 2013).

Nesse sentido, a delimitação de unidades de conservação de proteção integral em processos de compensação ambiental cria um erro de concepção, ao excluir categorias de unidades de conservação mais ajustadas à dinâmica socioecológica local. A criação de reservas extrativistas parece se configurar como um caminho direto para contextos como o do território Acaraí, ou de outros no litoral brasileiro (Burda \& Schiavetti, 2008), cujos territórios tradicionais se configuram como a base de sustentabilidade dos recursos naturais.

Ao mesmo tempo, há outra controvérsia, na forma de criação de reservas extrativistas. Como criar reservas extrativistas por meio de compensação ambiental, quando a sua criação depende de demanda dos próprios comunitários? Um dos ativos fundamentais dos modos de vida é o capital social, que é almejado no ato de criação de uma Resex. No entanto, a presença de laços comunitários, mecanismos de ação coletiva, associações e outras formas de organização comunitárias, podem não estar ajustados à lógica, ritos e tempos da criação das UCs, ou na via resultante, das demandas de re- 
categorização. Neste caso, poderia a compensação ambiental fomentar a construção de novas formas de capital social para a criação de Resex?

As Resex constituem-se como uma configuração institucional de maior potencial a compatibilizar conservação e desenvolvimento. Mas os conflitos de concepção entre a criação de UCs por compensação ambiental e a criação de Resex indicam que esta última não é em si a única saída. A fragilidade na aplicação do arcabouço legal pelos gestores ou outras organizações-ponte, como a Convenção 169 e a PNPCT, sobrecarrega as expectativas das reservas e menospreza os efeitos das medidas de compensação ambiental.

A PNPCT (Brasil, 2007) assimila outras dimensões fundamentais, como do autorreconhecimento e das territorialidades envolvidas, mas são atomizadas nos processos de operação da política ambiental, especialmente no cruzamento dos processos de licenciamento com as UCs. Esses processos esvaziam ainda mais as dimensões étnicas, simbólicas, relações de parentesco e de tradição envolvidas. Limitam-se a um enquadramento legal, dando um caráter excessivamente formal ao que se constitui na informalidade e a partir de outras epistemes.

\section{Referências}

Acselrad, H. Que é justiça ambiental. Rio de Janeiro: Garamond, 2009.

Acselrad, H.; Bezerra, G. das N. Desregulação, deslocalização e conflitos ambientais: considerações sobre o controle das demandas sociais, In: Almeida, A. W. B. et al. Capitalismo globalizado e recursos territoriais. Fronteiras da acumulação no Brasil Contemporâneo. Rio de Janeiro: Lamparina, p. 179-210, 2010.
Agrawal, A. Common Resources and Institutional Sustainability. In: Ostrom, E. et al. (Eds.). The drama of the commons. Committee on the Human Dimensions of Global Change. Washington: National Academy Press. p.41-86, 2002.

Allison, E. H.; Badjeck, M. C. Livelihoods, local knowledge and the integration of economic development and conservation concerns in the Lower Tana River Basin. Hydrobiologia, 527, 19-23, 2004.

Allison, E. H.; Ellis, F. The livelihoods approach and management of small-scale fisheries. Marine Policy, 25(5), 377-388, 2001.

Allison, E. H.; Horemans, B. Putting the principles of the Sustainable Livelihoods Approach into fisheries development policy and practice. Marine Policy, 30(6), 757-766, 2006.

Almeida, A. W. B. de. Conhecimento tradicional e biodiversidade: normas vigentes e propostas. 10 vol. Manaus: Programa de Pós-Graduação da Universidade do Amazonas - UEA/Programa de Pós-Graduação em Sociedade e Cultura da Amazônia / Fundação Ford / Fundação Universidade do Amazonas, 2008.

Almeida, A. W. B. de. Territórios E Territorialidades Específicas Na Amazônia: entre a "proteção" e o "protecionismo". CADERNO CRH, 25(64), 63-71, 2012.

Almudi, T.; Kalikoski, D. C. Homem e "natureza" em um parque nacional do sul do Brasil: meios de vida e conflitos nos arredores da Lagoa do Peixe. Desenvolvimento e Meio Ambiente, 20, 47-57, 2009. Disponível em: https://revistas. ufpr.br/made/article/view/12291

Almudi, T.; Kalikoski, D. C. Traditional fisherfolk and no-take protected areas: The Peixe Lagoon National Park dilemma. Ocean \& Coastal Management, 53, 5-6, 225-233, 2010.

Armitage, D. Building resilient livelihoods through adaptive co-management: the role of adaptive capacity. In: Armitage, D.; Berkes, F.; Doubleday, N. Adaptive Co- management: collaboration, learning, and multi-levei governance. Vancouver, UBCPress. p. 62-82, 2007.

Barreto, G. C. Dimensões humanas de áreas marinhas 
protegidas: uma revisão sistemática das definições e componentes. Pontal do Paraná, Dissertação (Mestrado em Sistemas Costeiros e Oceânicos) - UFPR, 2017.

Bavinck, M.; Berkes, F.; Charles, A.; Dias, A. C. E.; Doubleday, N.; Nayak, P.; Sowman, M. The impact of coastal grabbing on community conservation - a global reconnaissance. Maritime Studies, 16(8), 2017 doi: 10.1186/ s40152-017-0062-8 I

Bennett, N. J.; Dearden, P. From measuring outcomes to providing inputs: Governance, management, and local development for more effective marine protected areas. Marine Policy, 50, 96-110, 2014.

Berkes, F.; Colding, J.; Folke, C. Rediscovery of traditional ecological knowledge as adaptive management. Ecological Applications 10, 1251-1262, 2000. doi: 10.1890/1051-0761(2000)010[1251:ROTEKA]2.0.CO;2

Brasil. Constituição da República Federativa do Brasil, de 5 de outubro de 1988. Brasília: D.O.U. 191-A de 05/10/1988.

Brasil. Lei n. 9.985, de 18 de julho de 2000. Institui o Sistema Nacional de Unidades de Conservação da Natureza

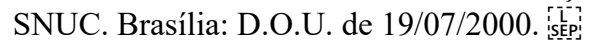

Brasil. Lei no 10.779, de 25 de novembro de 2003. Dispõe sobre a concessão do benefício de seguro desemprego, durante o período de defeso, ao pescador profissional que exerce a atividade pesqueira de forma artesanal. Brasília: D.O.U. de 26/11/2003.

Brasil. Lei n. 11.428, de 22 de dezembro de 2006. Dispõe sobre a utilização e proteção da vegetação nativa do Bioma Mata Atlântica, e dá outras providências. Brasília: D.O.U. de 26/12/2006.

Brasil. Decreto n. 6.040, de 07 de fevereiro de 2007. Institui a Política Nacional de Desenvolvimento Sustentável dos Povos e Comunidades Tradicionais. Brasília: D.O.U. de 08/02/2007.

Brasil. Lei Complementar $N^{\circ} 140$, de 8 de dezembro de 2011. Fixa normas, nos termos dos incisos III, VI e VII do caput e do parágrafo único do art. 23 da Constituição Federal; e altera a Lei no 6.938, de 31 de agosto de 1981. Brasília: D.O.U. de 09/12/2011.

Burda, C. L.; Schiavetti, A. Análise ecológica da pesca artesanal em quatro comunidades pesqueiras da Costa de Itacaré, Bahia, Brasil: Subsídios para a Gestão Territorial. Revista da Gestão Costeira Integrada, 8(2), 149-168, 2008.

Carlsson, L.; Berkes F. Co-management: concepts and methodological applications. Journal of Environmental Management, 75(1), 65-76, 2005.

Cash, D.; Adger, W. N.; Berkes, F. Scale and cross-scale dynamics: governance and information in a multilevel world. Ecology and Society, 11(2), 8, 2006. Disponível em http:// www.ecologyandsociety.org/vol11/iss2/art8/.

Cazella, A. A. Contribuições metodológicas da sócio-antropologia para o desenvolvimento territorial sustentável. EISFORIA, 4, n. especial, 225-247, 2006.

Chambers, R.; Conway, G. Sustaninable rural livelihoods: pratical concepts for the 21 st century. IDS Discussion paper, 296, 1991.

Chuenpagdee, R.; Jentoft, S. Step zero for fisheries co-management: What precedes implementation. Marine Policy, 31, 657-668, 2007. doi: 10.1016/j. marpol.2007.03.013

Chuenpagdee, R.; Pascual-Fernández, J. J.; Szeliánszky, E.; Luis Alegret, J.; Fraga, J.; Jentoft, S. Marine protected areas: Re-thinking their inception. Marine Policy, 39, 234-240, 2013. doi: 10.1016/j.marpol.2012.10.016.

CONAMA - Conselho Nacional do Meio Ambiente. Resolução $n .^{\circ} 428$, de 17 de dezembro de 2010.

Diegues, A. C. S. O Mito Moderno da Teoria da Natureza Intocada. São Paulo: Hucitec, 1996.

Diegues, A. C. S. Human populations and coastal wetlands: conservation and management in Brazil. Ocean \& Coastal Management, 42(2-4), 187-210, 1999.

Diegues, A. C. S. Sociobiodiversidade. In: Ferraro Junior, L. A. (Org.). Encontros e caminhos: formação de educadoras(es) ambientais e coletivos educadores. Brasilia: MMA, Diretoria de Educação Ambiental, p. 303-312, 2005.

Diegues, A. C. Marine Protected Areas and Artisanal Fisheries in Brazil. Samudra Monographs. Chennai: International Collective in Support of Fishworkers, 2008.

Drummond Câmara, J. B. Governança ambiental no Brasil: ecos do passado. Revista De Sociologia E Política, 21(46), 
125-146, 2013.

Ellis, F.; Allison, E. Livelihood diversification and natural resource access. Overseas Development Group University of East Anglia UK. FAO. Livelihood Support Programme (LSP), 2004.

FAO. Fisheries management. 4. Marine protected areas and fisheries. Ed. FAO, 2011.

Farrington, J. et al. Sustainable Livelihoods In Practice: Early Applications of Concepts In Rural Areas. Natural Resource perspectives, 42, June, 1999.

Folke, C.; Pritchard, L. Jr.; Berkes, F.; Colding, J.; Svedin, $\mathrm{U}$. The Problem of fit between ecosystem and institutions. IHDP Working Paper 2, 1-35, 1998.

Folke, C.; Pritchard, L. Jr.; Berkes, F.; Colding, J.; Svedin, $\mathrm{U}$. The problem of fit between ecosystems and institutions: ten years later. $E \& S 12,38,2007$.

Foppa, C. C. Comunidades pesqueiras e a construção de territórios sustentáveis na zona costeira: uma leitura a partir da Área de Proteção Ambiental da Costa Brava em Balneário Camboriú/SC. Florianópolis, Dissertação (Mestrado Profissional em Planejamento Territorial e Desenvolvimento Sócio-Ambiental) - UDESC, 2009.

Foppa, C. C. Comunidades tradicionais em movimento: modos de vida e Educação Ambiental para o desenvolvimento territorial sustentável em uma unidade de conservação marinho-costeira no litoral de Santa Catarina. Rio Grande, Tese (Doutorado Educação Ambiental) - FURG, 2015.

Foppa, C. C.; Medeiros, R. P. Nosso Acaraí. Dinâmica socioecológica e relações territoriais das populações tradicionais da área de entorno do Rio Acaraí, município de São Francisco (SC). Relatório técnico apresentado aos autos da Ação Civil Pública Número: 061.07.009145-6. Ministério Público Estadual/FATMA. Itajai: UNIVALI. 2011. p. 157.

Foppa, C. C.; Medeiros, R. P. A construção de territórios sustentáveis na zona costeira: a criação e gestão de unidades de conservação. Anais Congresso Brasileiro de Oceanografia, 2012.

Hallam, M. K.; Bennett, N. J. Adaptive social impact management for conservation and environmental management. Conservation Biology, 32, 304-314, 2018. doi: 10.1111/ cobi. 12985

Holling, C. S.; Meffe, G. K. Command and control and the pathology of natural resource management. Conservation Biology, 10, 328-37, 1996.

Holling, C. S.; Berkes, F.; Folke, C. Science, sustainability and resource management. In: Berkes, F.; Folke, C. Linking Social and Ecological Systems: management practices and Social Mechanisms for building resilience. Cambridge University Press, p. 342-361, 1998.

ICMBio - Instituto Chico Mendes de Conservação da Biodiversidade. Disponível em: http://www.icmbio.gov.br/ portal/biodiversidade/unidades-de-conservacao/planos-demanejo.html. Acesso em: dez. 2014.

Kalikoski, D. C.; Vasconcellos, M. Case study of the technical, socio-economic and environmental conditions of small-scale fisheries in the estuary of Patos Lagoon, Brazil. FAO Fisheries and Aquaculture Circular 1075 - FIRO/ C1075, 190, 2012.

Kalikoski, D. C.; Seixas, C. S.; Almudi, T. Gestão compartilhada e comunitária da pesca no Brasil: avanços e desafios. Ambiente \& Sociedade, 12, 151-172, 2009.

Knutsson, P. The sustainable livelihoods approach: A framework for knowledge integration assessment. Human Ecology Review, 13(1), 90-99, 2006.

Medeiros, R. P. Possibilidades e obstáculos à co-gestão adaptativa de sistemas pesqueiros artesanais: estudo de caso na área da Baía de Tijucas, litoral centro- norte do estado de Santa Catarina, no período de 2004 a 2008. Tese (Doutorado em Sociologia Política) - UFSC, 2009.

Morales, E. M. Q.; Lepofsky, D.; Berkes, F. Ethnobiology and Fisheries: Learning from the Past for the Present. Journal of Ethnobiology, 37, 369-379, 2017. doi: 10.2993/02780771-37.3.369

O'Riordan, T. Environmental science on the move. In: O'Riordan, T. Environmental science for environmental management. Prentice Hall. 2000.

Queiroz, H. L. A reserva de desenvolvimento sustentável de Mamirauá. Estudos Avançados, 19(54), 183-203, 2005.

Sabourin, E. E.; Teixeira, O. A. Planejamento e Desenvol- 
vimento dos Territórios Rurais. Conceitos, controvérsias e experiências. Brasilia: Emprapa Informação Tecnológica, 2002.

Sachs, I. Ecodesenvolvimento: crescer sem destruir. São Paulo: Vértice, 1986.

Scoones, I. Sustainable Rural Livelihoods: A Framework for Analysise, Working Paper 72, Brighton, UK: Institute for Development Studies. Ids Working Paper, 72, 1998.

Sen, A. Desenvolvimento Como Liberdade. São Paulo: Companhia das Letras, 2000.

Sen, S.; Nielsen, J. R. Fisheries co-management: a comparative analysis. Marine Policy, 20(5), 405-418, 1996.

Spalonese, M. B. Desamparados nas grotas do Estado: os contratempos da sobreposição entre o território quilombola de São Roque e os Parques Nacionais de Aparados da Serra e da Serra Geral. RURIS, 7(2), 33-56, 2013.

Vivacqua, M. Conflitos socioambientais no litoral de Santa Catarina: o caso da Reserva Biológica Marinha do Arvoredo. Florianópolis, Dissertação (Mestrado em Sociologia Política) - UFSC, 2005.

Vivacqua, M. Dilemas da conservação e desenvolvimento na gestão compartilhada da pesca artesanal: conflitos e sinergias nos processos de criação de Reservas Extrativistas Marinho-Costeiras em Santa Catarina. Florianópolis, Tese (Doutorado em Sociologia Política) - UFSC, 2012.

Vieira, L.; Cader, R. A política ambiental na década 20022012. In: Sader, E. (Org.). 10 anos de governos pós-neoliberais no Brasil: Lula e Dilma. São Paulo, SP: Boitempo; Rio de Janeiro: FLACSO Brasil, p. 225-238, 2013.

Vieira, P. F.; Cazella, A. A. Modelo de Análise do projeto de pesquisa Desenvolvimento Territorial Sustentável: diagnóstico de potencialidades e obstáculos e zonas rurais dos estados da Paraíba e Santa Catarina - Projeto CAPES/ COFECUB n. 449/2004. UFSC.

Vieira, P. F.; Cazella, A. A.; Cerdan, C. Desenvolvimento territorial sustentável: conceitos, experiências e desafios teórico-metodológicos. Eisforia, 4(4), 13-22, 2006.

Westlund, L.; Charles, A.; Garcia, S. M.; Sanders, J. Marine protected areas: Interactions with fishery livelihoods and food security. FAO Fisheries and Aquaculture Technical Paper: 603, 2017. Disponível em: http://www.fao.org/3/a-i6742e.pdf 